\title{
TTR
}

Traduction, terminologie, re?daction

\section{Processus d'acculturation et problèmes de traduction : le théâtre de Wole Soyinka}

\section{Éliane Saint-André Utudjian}

Volume 6, numéro 2, 2e semestre 1993

Traduction, mixité, politique

URI : https://id.erudit.org/iderudit/037152ar

DOI : https://doi.org/10.7202/037152ar

Aller au sommaire du numéro

Éditeur(s)

Association canadienne de traductologie

ISSN

0835-8443 (imprimé)

1708-2188 (numérique)

Découvrir la revue

\section{Citer cet article}

Saint-André Utudjian, É. (1993). Processus d'acculturation et problèmes de traduction : le théâtre de Wole Soyinka. TTR, 6(2), 79-101.

https://doi.org/10.7202/037152ar

\section{Résumé de l'article}

Processus d'acculturation et problèmes de traduction : le théâtre de WoIe Soyinka - Cette étude traite des déterminations linguistiques et culturelles que fait peser une culture-source peu familière sur la traduction en français du théâtre de langue anglaise de l'auteur nigérian WoIe Soyinka, prix Nobel de littérature (1986). L'ethnie yoruba fournit à ces pièces une langue polytonale, une civilisation enracinée dans le sacré et un théâtre ambulant opératique. Les influences occidentales se reconnaissent à l'utilisation de l'anglais standard par les personnages membres de l'élite cultivée, de mots-clés révélateurs d'idéologies par les personnages représentatifs et de modèles littéraires occidentaux. La composante anglo-nigériane, synthèse plus ou moins cohérente, mais toujours très riche, de toutes les influences, se distingue par l'emploi de l'anglais pidgin, d'un anglais nigérianisé et d'un style heurté, parfois hermétique, exprimant la souffrance et la rébellion. Les trois composantes de ce théâtre (indissociables dans la réalité) exigent du traducteur des techniques variées, une culture étendue et une grande sensibilité poétique. Il revient au traducteur francophone de trouver des équivalents français susceptibles de rendre des faits de civilisation africains, issus de processus d'acculturation complexes.
Tous droits réservés @ C TTR: traduction, terminologie, rédaction — Les auteurs, 1993
Cest protégé par la loi sur le droit d'auteur. L’utilisation des services d'Érudit (y compris la reproduction) est assujettie à sa politique d'utilisation que vous pouvez consulter en ligne.

https://apropos.erudit.org/fr/usagers/politique-dutilisation/ 


\section{Processus d'acculturation et problèmes de traduction: le théâtre de Wole Soyinka}

\section{Éliane Saint-André Utudjian}

\section{Introduction}

La traduction de pièces de thêatre requiert un travail linguistique et une activité de critique dramatique sur les significations $d^{\prime} œ u v r e s$ inscrites dans un contexte linguistique et culturel toujours très spécifique, leur imposant de multiples déterminations, plus encore lorsqu'il s'agit du théâtre d'une aire culturelle peu familière. Ainsi, pour cerner les déterminations conditionnant la traduction en français du théâtre nigérian d'expression anglaise, convient-il de définir l'originalité linguistique et culturelle de ce théâtre à la fois africain et anglophone, en s'attachant plus particulièrement à l'impact des données, complexes et même parfois contradictoires, de la ou des culturessources sur la ou les cultures-cibles. J'axerai donc mon étude du théâtre du dramaturge nigérian anglophone Wole Soyinka sur l'originalité de la culture-source à laquelle est confronté le traducteur francophone de ce célèbre auteur dramatique, prix Nobel de littérature (1986).

Déterminé par sa langue et sa culture (la culture-cible), le lecteur français trouve parfois incompréhensibles des traductions en partie déterminées par une culture-source se rattachant à une communauté nationale mal connue de l'Occident (bien que forte de quelque 100 millions d'âmes) et, qui plus est, insolite. Au regard inaverti d'un Occidental, la langue et la culture qui 
sous-tendent ainsi le théâtre de Wole Soyinka et sa traduction française offrent, au pire, une vision incohérente et, au mieux, une vision ésotérique. Dans la Récolte de Kongi, par exemple, les chants nostalgiques et les propos désabusés d'un ancien despote détrôné (l'oba Danlola) se mêlent, de la façon la plus contradictoire, la plus paradoxale, la plus absurde même, estime le lecteur/ spectateur dérouté, à la rhétorique creuse et à la crise d'épilepsie du nouveau tyran (Kongi, le Président d'Isma), sur un fond hybride de langues anglaise et yoruba, de musique africaine traditionnelle et d'airs modernes de highlife (musique de cabaret d'origine ghanéenne), de rituels yoruba et de liturgie chrétienne, sous un régime politique sanguinaire habilement soutenu par les médias et au milieu d'espérances démocratiques entretenues par l'héritier du roi déchu, par sa maîtresse (symbole de vie et d'amour) et par le peuple (symbole du Nigéria de demain). De même, dans Fous et Spécialistes, une des œuvres les plus difficiles de Wole Soyinka, la nouvelle et sinistre religion de "Comme», inféodée à tous les dogmes, toutes les hypocrisies et tous les abus de pouvoir et épousée par le $D^{r}$ Béro, l'un des fous et spécialistes de la pièce, menace de mort le culte traditionnel de la Terre, jalousement gardé par les Mères Terrestres, magiciennes rendues à demi impuissantes par l'universelle anomie des temps modernes. Le vent de folie qui souffle sur tous les personnages, mendiants et puissants, exploités et exploitants, défie la compréhension.

\section{Wole Soyinka: un double héritage culturel}

Né en 1934, au sein de l'ethnie yoruba, dans les environs d'Abéokuta, au sud-ouest du Nigéria, Wole Soyinka, enfant, fréquenta à Isara, dans sa famille paternelle, d'origine ijebu (les Ijebu sont un rameau des Yoruba), le milieu yoruba traditionnel, fut initié aux arcanes de la langue polytonale yoruba, au culte et aux croyances de son ethnie, et participa aux danses masquées des Egungun, danses rituelles liées au culte des Morts. Il apprit le langage des tambours-parlants, mémorisa les contes, les proverbes, les chants et les incantations de l'«orature" (ou littérature orale) yoruba et assista aux représentations théâtrales données à travers tout le pays yoruba par des troupes ambu- 
lantes, héritières du théâtre traditionnel. D'autre part, fils d'un converti, directeur d'école austère et exigeant, en poste à Aké parmi les Egba (autre rameau, plus occidentalisé, des Yoruba), et $\mathrm{d}^{\prime}$ une mère egba commerçante, qui militait dans des associations de femmes, Wole Soyinka reçut une éducation formelle de type occidental dans le foyer chrétien de ses parents, dans l'école confessionnelle de son père et au lycée d'Abéokuta. Il fit ses

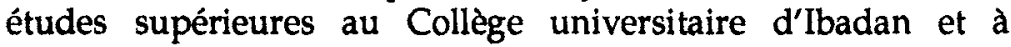
l'Université de Leeds. Son intérêt pour le théâtre lui inspira ses premières pièces en 1958-59, alors qu'il assurait les fonctions de lecteur au Royal Court Theatre de Londres et s'y familiarisait avec le thêatre occidental d'avant-garde (Pinter, Albee, Brecht et Beckett). Après son retour au Nigéria en 1960, l'année où fut proclamée l'indépendance de ce pays, une bourse lui permit d'étudier le théâtre traditionnel ouest-africain; il fonda et dirigea deux troupes thêâtrales, exerça les fonctions de metteur en scène, directeur de théâtre, acteur et même cinéaste; il assura la supervision de la police routière de son État; au cours d'une longue et brillante carrière, ponctuée de voyages, de conférences et de séjours d'études à travers le monde, il occupa diverses chaires d'enseignement, à l'Université d'lbadan, d'lfe, de Cambridge, et de nouveau au Nigéria; et, sans interruption, il poursuivit son œuvre pionnière de création dramatique et théâtrale. Lors de la guerre civile nigériane (1967-1970), il purgea une peine de prison pour s'être interposé entre les deux camps ennemis. En 1986, enfin, lui fut décerné le prix Nobel de littérature.

\section{Les œuvres dramatiques et leurs traductions françaises}

La simple énumération des traductions françaises connues à ce jour du théâtre de Soyinka montrera que son cuvre dramatique, maintenant entièrement traduite en français (à une ou deux exceptions près), offre un important corpus à la réflexion du traductologue.

L'œuvre dramatique de Wole Soyinka, dont les représentations et les publications s'étendent de 1958 à aujourd'hui, représente environ trente-cinq années d'invention théâtrale. Le 
prix Nobel qui fut décerné à Wole Soyinka marquait donc la consécration d'une carrière déjà longue et fructueuse. De plus, entre 1968 et 1971, surgit une première vague, encore modeste, de traductions françaises des œuvres du dramaturge, avec le Lion et la Perle (1968), la Danse de la Forêt (1971) et les Gens des Marais, Un Sang Fort et les Tribulations de Frère Jéro (1971).

Après un silence de quinze années, probablement stimulés par l'attribution de la plus prestigieuse des récompenses littéraires à l'écrivain nigérian, traducteurs et éditeurs francophones poursuivirent avec un nouvel enthousiasme la tâche des années 1968-1971. Ainsi, de 1986 à 1990, furent publiées les Métamorphoses de Frère jéro (1986), la Mort et l'Écuyer du Roi (1986), la Route (1988), la Récolte de Kongi (1988), les Bacchantes d'Euripide (1989), Requiem pour un Futurologue (1990), Du Rouge de Cam sur les Feuilles (1990), Fous et Spécialistes (1990).

Ces pièces défient constamment le traducteur, qu'elles confrontent au mélange des langues, à la diversité des niveaux de langue, à la multiplicité des registres linguistiques, à l'accumulation des effets stylistiques, à l'hétérogénéité des cultures et à la complexité des formes théâtrales.

\section{La double composante du théâtre de Wole Soyinka}

De la biographie de l'auteur nigérian et de la culture véhiculée par ses pièces de théâtre, il ressort que son héritage linguistique, intellectuel, culturel et spirituel, particulièrement complexe, se rattache à la fois à la langue et la culture yoruba, à la langue et la culture anglaises et à la culture anglo-nigériane.

\section{1) La composante yoruba}

A ses origines yoruba, Wole Soyinka est redevable d'une langue, une religion, des coutumes et des formes théâtrales très particulières, méconnues de l'Occident et pour ainsi dire impossibles à transposer autrement que par des à-peu-près dans l'aire culturelle si différente de la culture-cible. 


\section{a) La langue}

Le yoruba sert à ancrer les répliques des personnages dans le milieu dont il véhicule la culture. Diverses techniques accompagnent l'emploi de la langue maternelle de l'auteur dans un théâtre d'expression essentiellement anglaise, qui d'ailleurs n'est parfois (mais pas toujours) que la traduction d'une pensée formulée en yoruba. Les termes yoruba isolés que n'explicite aucune traduction sont censés être déduits du contexte: dans la Récolte de Kangi, par crainte qu'il ne s'enfuie, l'ancien oba (ou roi) écroué a été dévêtu de son pantalon "national» (ironiquement, après le coup d'État du Président Kongi, la République prétendument démocratique d'Isma s'est appropriée jusqu'aux vêtements de l'ancien roi); sous son agbada (on doit comprendre, sa longue robe flottante), le dignitaire déchu s'est enveloppé les jambes d'un lambeau du drapeau national (évidemment par raillerie), un oba ne devant pas se donner en spectacle au monde l'ogolonto (tout nu) $(1990$, p. 6). Un autre procédé consiste à donner une traduction interne des mots yoruba; dans Fous et Spécialistes, la rengaine d'origine biblique évocatrice du cycle ininterrompu de la bêtise humaine, avec ses intransigeances et son dogmatisme, est d'abord l'objet de commentaires en anglais sur le cycle complet de "Comme», "Comme» qui "était - est - maintenant sera - dans les siècles des siècles», immuablement et à tout jamais, avant que ne retentisse, chanté en yoruba, l'air de «Bio o ti wa", qui reprend les mêmes paroles (1990, pp. 45-46). L'auteur peut aussi traduire les termes yoruba descriptifs de la vie locale en note ou dans un glossaire, méthode utile au lecteur, mais inutilisable sur une scène de théatre. Pour introduire la faune, la flore, les coutumes vestimentaires et alimentaires, les mille gestes de la vie quotidienne et les pratiques religieuses des Yoruba, seuls semblent convenir des termes yoruba, même si l'étranger a peine à se représenter tous ces objets inconnus, intraduisibles dans les langues européennes, ainsi les tambours bata et gbedu, l'araba (roi des arbres, dédié à une divinité), l'opele (chapelet utilisé en divination) et le sigidi (figurine sculptée, investie de pouvoirs magiques). 
Les faits de civilisation sont encore plus difficiles à saisir que les mots isolés; dans les Tribulations de Frère Jéro, une note explique l'attitude insolente d'un gamin des rues qui ne se contente pas de battre du tambour pour mendier, mais qui, se conformant à une coutume locale, tambourine des insultes à l'intention d'Amopé, la marchande. Une note des Métamorphoses de Frère Jéro commente une autre pratique, plus sinistre, les Bar Beach Shows ou les exécutions publiques sur les plages de Lagos, l'ancienne capitale nigériane. La Route, la Mort et l'Écuyer du Roi et Opéra Wonyosi sont accompagnées d'un glossaire décrivant en anglais certaines expressions et coutumes nigérianes figurant dans le texte sous une appellation locale, yoruba ou anglaise, (faranse, représentant les Africains francophones - les «Français» -; ogah sah, signifiant «Monsieur, grand Chef» et oga sa «le grand chef prend ses jambes à son coù; lkoyi décrite comme une banlieue très résidentielle de Lagos; Sango étant le dieu du tonnerre et des éclairs; l'osugbo, enfin, décrit comme un culte terrifiant comportant des exécutions). Lorsqu'il s'agit de chants, l'auteur en indique la traduction anglaise à la fin de la pièce (par exemple, dans la Route et dans Du Rouge de Cam sur les Feuilles) ou en regard du texte yoruba (par exemple, dans la Récolte de Kongi); par contre, dans la Danse de la Forêt et dans la Mort et $l^{\prime} E ́ c u y e r d u$ Roi, seul le texte anglais des chants, d'une grande beauté et puissamment suggestifs, figure, peut-être parce que, si les chants très nombreux étaient tous transcrits en yoruba, cette langue occuperait une place trop importante par rapport à la langue de création dramatique choisie par l'auteur, l'anglais; de toutes façons, la partition musicale n'est jamais fournie, probablement faute d'une notation adéquate de la musique africaine; infiniment rares seraient d'ailleurs, en Occident du moins, les orchestres (yoruba) capables de la jouer. Ainsi, seuls les sonorités et le schéma rythmique des chants et des danses de l'ancien roi apparaissent dans le texte suivant, tiré de la Récolte de Kongi:

(L'oba exécute à pas lents une danse royale au rythme du tambour gbedu) ema 'gun 'yan oba kere o (bis)/... Orisa l'oba.

Ce texte étant accompagné d'une traduction anglaise, riche en suggestions, la traduction française de cet oriki ou chant de louanges adressé au vieux chef traditionnel Danlola, risque de 
s'appuyer sur le seul texte anglais et de n'être donc qu'une traduction au deuxième degré, ne rendant ni les tons, ni les rythmes, ni la poésie du chant original:

Ne pilez pas l'igname du roi dans un mortier de petite taille ... le roi est un Dieu.

D'ailleurs, pour les besoins de la communication avec un public suffisamment large et parce que le poète Wole Soyinka se plaît à versifier en anglais, très souvent il transpose avec le plus grand bonheur les échanges entre les Yoruba et leurs divinités dans un mètre anglais; ainsi, l'incantation par laquelle l'exorciste de la Danse de la Forêt engage les Morts à participer à la fête des Vivants est-elle rendue par l'auteur dans une simple version anglaise (que la traductrice francophone s'est efforcé de transposer en un style poétique):

Place! Place! / J'ai senti l'haleine du vent. Assez./ Écartez-vous. Laissez aux morts/ La place de danser/ $\mathrm{Si}$ tu vois la feuille du bananier/ Déchiquetée, effilochée, / Pendre mouillée comme un voile de deuil. N'accuse pas le vent. Laissez aux morts/ La place de danser! (1971, p. 72)

En tant que véhicule du sacré, une langue africaine se prête très mal aux transpositions et aux adaptations dans une autre langue. Selon Holas, en Afrique, «La parole bien dite, et au moment juste, a valeur de l'acte lui-même» (Houis, p. 56). Ainsi, l'homme établit son pouvoir sur les choses par la parole, qui est donc sacrée. C'est peut-être la raison pour laquelle Wole Soyinka estime inutile, dans Fous et spécialistes ${ }^{1}$, de traduire en anglais les incantations à l'aide desquelles les Mères terrestres entrent en contact avec les Puissances numineuses.

1. Wole Soyinka, Six Plays (Methuen, 1984), p. 234. 


\section{b) La civilisation}

Wole Soyinka apparaît comme l'héritier non seulement de la langue yoruba mais aussi de la civilisation qu'elle véhicule, l'une des plus anciennes et des plus riches de l'Afrique de l'Ouest, renommée pour sa statuaire et ses masques (Ifé, Bénin), le faste de ses oba et de ses bale (chefs), son panthéon dominé par le dieu du fer et des chauffeurs, Ogun, à qui on sacrifie des chiens et en l'honneur de qui coule le vin de palme, par le dieu du tonnerre et de l'électricité, Shango, et par un dieu fantasque, Eshu. Les divinités interviennent constamment dans ces pièces, et les rituels structurent le théâtre véritablement "métaphysique» de Wole Soyinka.

Les rites funéraires, agraires, sacrificatoires et purificatoires des collectivités yoruba traditionnelles $s^{\prime}$ accomplissent le plus souvent à l'abri des regards profanes, dans des espaces sacrés (comme le coin de forêt réservé aux dieux dans la Danse de la Forêt). Prennent part à ces cérémonies non seulement les membres initiés de la communauté, mais encore les esprits des ancêtres et des morts, des enfants à naître et toutes sortes de forces surnaturelles qui s'incarnent dans des mascarades. Ce sont ces croyances que met en scène le dramaturge lorsqu'il laisse les divinités et les êtres étrangement masqués, revenants, esprits, lutins et gnomes, qui hantent le cœeur de la forêt, intervenir dans la vie des humains et les guider dans leur parcours initiatique. Les invités des augustes Habitants de la forêt, masqués sur l'ordre de la divinité suprême (Olodumaré), sont investis par des forces cosmiques auxquelles ils prêtent leur voix, les mouvements de leur corps, les battements de leurs tambours et le langage des tambours-parlants. Le rituel d'une nuit aura ainsi amené le héros, le sculpteur Démoké, le protégé d'Ogun, à interpréter le message des dieux et prendre conscience de ses responsabilités, en tant qu'artiste, vis-à-vis des autres hommes. De même, dans la Race forte et la Route se déroulent des rituels libérateurs qui mènent les héros et leur communauté sur la voie du salut. Certaines coutumes, par contre, loin de stimuler l'imagination du lecteur/ spectateur occidental, lui paraissent choquantes: les références aux pets, symboles de vanité et de vide moral, embarrassent le 
lecteur et le traducteur de Fous et Spécialistes; mais de telles fonctions mentionnées par sarcasme sont considérées comme des actes naturels et utilisées comme source d'un comique grinçant; dans la Récolte de Kongi, l'aba Danlola en personne n'éprouve aucune gêne à décrire ses royales défécations:

Quand un oba arrête la procession et s'accroupit au bord de la

C'est pour un besoin pressant route]

Qui n'épargne ni les rois ni les dieux

Les hommes sages tournent la tête

Jusqu'à ce qu'il se soit essuyé le derrière. (1988, p. 4)

\section{c) Le théâtre yoruba}

Imprégné de langue et de culture yoruba, le théâtre de Wole Soyinka emprunte également son inspiration aux formes théâtrales propres à son ethnie. Depuis plusieurs siècles, le pays yoruba possède aussi des activités théâtrales ayant leurs lieux scéniques, leurs répertoires, leurs acteurs professionnels, souvent ambulants, leurs masques, leurs orchestres, leurs chœurs, leurs ballets et leur public de spectateurs-participants. Le théâtre traditionnel est régi par des conventions immuables et comporte ses stéréotypes (hommes et bêtes) reconnaissables à leurs voix, leurs déguisements, leurs mimiques faciales et leurs comportements propres. L'ordre d'apparition des personnages et des séquences dramatiques, la succession des danses et des chants, des soli, des chœurs et des sketches satiriques obéissent aux règles du genre, fixées par la coutume, entre autres dans le théâtre alarinjo. Par les échanges qui s'instaurent entre acteurs et spectateurs, des communautés entières se remettent en cause. La portée de ce théâtre est à la fois sociale, éthique et cosmique. Wole Soyinka garde certainement le souvenir des spectacles donnés par les troupes alarinjo et apidan auxquels il assista dans son enfance. S'inspirant des modèles traditionnels, il adapte à des cuvres imprégnées d'une idéologie très moderne des techniques empruntées au théâtre yoruba. La Récolte de Kongi consiste en une suite de vignettes satiriques adaptées des sketches du théâtre apidan. À travers des portraits stéréotypés, les revues de ce théâtre satirisaient des types sociaux comme la mégère, le vaniteux et le politicien véreux. De même, Danlola et Kongi, 
respectivement les représentants de l'ordre ancien et de l'ordre nouveau, incarnent tous deux le type du tyran, cruel, égoïste, vaniteux et sensuel, dont le prototype mythologique est Eshu et le prototype moderne Kwamé Nkrumah (premier Président du Ghana, peu apprécié de Wole Soyinka). Si le vieil oba est dépeint avec une ironie indulgente, Wole Soyinka brosse un portrait impitoyable du despote d'Isma, réplique moderne du roi "Cannibale» Mata Kharibu de la Danse de la Forêt. Dans la Récolte de Kongi, la satire se dégage des parallèles et des oppositions entre la chefferie traditionnelle, le régime présidentiel d'un nouveau Kwamé Nkrumah et la vision de l'avenir entretenue par Daodu, le neveu de l'Oba. L'action s'articule sur un jeu dialectique entre les forces de mort, incarnées par le sinistre Président $\mathrm{d}^{\prime}$ Isma, et les forces de vie, symbolisées par Daodu. Dans ses plus beaux moments, cette tragi-comédie musicale est un véritable hymne à la vie et une célébration de l'amour, des plaisirs d'une table remplie de mets du pays, ignames, tarots, poisson fumé et vin de palme, et des autres joies de la vie (1988, p. 74): «Il faut prêcher la vie... et rien que la vie» (1988, p. 44). Fous et Spécialistes, œuvre postérieure à la guerre civile, particulièrement désabusée, met en scène des fous dévoyés, parfois pervers, comme le $D^{r}$ Béro, le Spécialiste, et toujours nocifs, comme le père de Béro, le Vieillard, qui veut le bien, mais cause le mal, par impuissance. Les mendiants, indifféremment au service du Vieillard et de son monstre de fils, sont les dignes fils de la divinité Obatala, protectrice des albinos, des bossus, des nains et de tous les handicapés. Leurs origines divines prêtent à ces rebuts $d$ 'humanité une dimension inattendue.

\section{d) Les «opéras» yoruba}

De plus, ce qui échappe en général au lecteur et au traducteur des pièces de Wole Soyinka, c'est leur caractère opératique, qui les apparente aux grandes fêtes et aux rituels des communautés traditionnelles. Du Prologue à l'Épilogue, la Récolte de Kongi, loin de n'être qu'une sinistre farce, retentit des roulements de tambours, du pincement des guitares, des sonneries des cors, du martèlement des pilons dans les mortiers, des coups de sifflets, du brouhaha des réjouissances publiques, du fracas métallique de 
portes de prison qui se ferment sur leurs prisonniers, de chants traditionnels et de rengaines contemporaines. Aussi cette pièce a-t-elle été décrite comme uune sorte de comédie musicale politique ${ }^{2} »$. Ce drame musical commence par un hymne parodique dans lequel, sur un air traditionnel, l'oba et sa suite raillent, en anglais, mais dans une langue imagée suggérant le parler des Anciens, le nouveau régime du Président Kongi. Suit, dans la même scène, une danse accompagnant les oriki du roi, chantés en yoruba, au rythme des tambours royaux, les tambours gbedu. Le Prologue se termine par un chant et une danse funèbres, l'ege, qui introduit le thème du déclin de la royauté traditionnelle. Dans la Deuxième Partie, la scène des préparatifs de la Fête de l'Igname comporte une autre série de chants traditionnels en yoruba que font retentir, à la gloire de Danlola, ses femmes et son babalawo (ou griot). Des allusions y sont faites au Dieu Ogun et au roi-Dieu Sango, ainsi qu'à des coutumes yoruba, exactement comme dans les revues théâtrales alarinjo. Quand commence la fête elle-même, le grand tambour de parade retentit, accompagné de coups de sifflets stridents annonçant l'arrivée de la Brigade des Menuisiers. Leur chant, d'une naïveté enfantine, a perdu, comme le règne du nouveau despote, tout caractère traditionnel. Le dernier chant, le chant de la Récolte, est chanté en yoruba par le Corps des Femmes, au rythme des pilons qui écrasent l'Igname nouvelle, au milieu des danses, des battements de tambours, des festins et des réjouissances populaires. Dans cette cuvre, comme déjà dans la Danse de la Forêt, comme dans la plus somptueuse et la plus poétique de ses tragédies, la Mort et l'Écuyer du Roi, et comme dans la comédie parodique intitulée Opéra Wonyosi, l'art de Wole Soyinka s'achemine vers cette forme de théâtre total, vers laquelle tendaient déjà les "opéras» des musiciens yoruba des années 1940-60, Kola Ogunmola et Duro Ladipo. Dans un tel théâtre, danses, chants et mascarades finissent par se confondre avec la structure même des pièces. Que reste-t-il néanmoins de la dimension opératique dans la traduction française d'une œuvre de Wole Soyinka?

2. Gerald Moore, "A Sort of African political musical», Wole Soyinka (Londres, Evans Brothers, 1971), p. 71. 
L'utilisation de l'anglais par un auteur africain pose souvent les mêmes problèmes que son emploi par n'importe quel autre auteur anglophone. L'héritage linguistique, intellectuel, culturel et spirituel de Wole Soyinka est, dans une large mesure, celui d'un universitaire cultivé, de langue anglaise. À cet égard, les problèmes que posent sa langue et sa pensée au traducteur francophone ne diffèrent nullement des difficultés confrontant tout traducteur du théâtre de langue anglaise en français. Dans ce cas, en dépit des différences qui opposent les deux langues et les deux cultures, l'anglais et le français demeurent des langues européennes parlées par des peuples appartenant à la même civilisation occidentale. La composante «anglaise» appelle néanmoins quelques remarques.

\section{a) Le mot-clé et la puissance du verbe}

L'anglais standard figure en bonne place dans les pièces de Wole Soyinka. Il convient plus particulièrement aux intellectuels et autres personnages - prêtres, fonctionnaires gouvernementaux, bourgeois, notables, responsables politiques, hommes au pouvoir, médecins et enseignants - dont l'éducation à l'occidentale leur permet de s'exprimer dans la langue parfaitement correcte et idiomatique de l'Anglophone cultivé.

Face à l'insistance sur certains mots et à leur répétition, le traducteur doit se garder des interférences et avoir présent à l'esprit la valeur de la parole dans les sociétés africaines. C'est ainsi que sur le plan lexical, le mot anglais «harvest» qui se traduit par «moisson» dans nos pays producteurs de céréales, évoque plutôt le terme de «récolte» au pays de l'igname, qui est le roi des tubercules en Afrique. Il s'agit en réalité d'un mot-clé de la Récolte de Kongi, œuvre dominée par le désir incontrôlable du nouveau Président d'Isma de recevoir rituellement des mains de l'ancien roi l'igname nouvelle, dans l'espoir qu'en sa personne, incarnation de l'Esprit de la Récolte, se concentreront les pouvoirs traditionnels et le pouvoir présidentiel. L'auteur possède l'art de composer des scènes entières autour d'un mot- 
clé, qui doit donc revêtir une importance cruciale dans la traduction. Dans une séquence d'une violence contenue, dont le modèle est emprunté aux jeux de rôles du théâtre alarinjo, les mendiants de Fous et Spécialistes jouent le sketch de «la Vérité», Aafaa incarnant le Spécialiste en train de lui faire avouer «la Vérité»:

Tu ne dois pas penser que $c^{\prime}$ est moi qui te fais mal, mais que c'est la Vérité qui fait mal. Nous sommes tous à la recherche de la Vérité. Je suis le Spécialiste de la Vérité. Maintenant, est-ce qu'il nous faudra enfoncer la seringue, toute la seringue? $\mathrm{Ou}$ bien aurons-nous la Vérité, toute la Vérité? (II enfonce la seringue plus profondément encore. Goyi hurle, puis sa tête retombe lourdement.) (1990, p. 21)

\section{b) Les sources littéraires occidentales}

Le théâtre de Wole Soyinka possède de nombreuses sources littéraires contemporaines, européennes et américaines, de Caligula d'Albert Camus à la Vie de Galilée et la Résistible Ascension $d^{\prime}$ Arturo Ui de Bertolt Brecht. Kongi, le tyran sanguinaire de Wole Soyinka, présenté mensongèrement par ses conseillers comme le bienveillant Père de la nation, est la copie conforme de Caligula. Il est en outre un personnage brechtien, en ce sens, du moins, qu'il produit un effet de distanciation: le spectateur n'éprouve ni admiration, ni compassion pour lui.

Les réminiscences de Shakespeare sous-tendent la langue, la caractérisation et les structures dramatiques du théátre de Wole Soyinka. Les mères terrestres, (les deux sorcières hiératiques de Fous et Spécialistes) rappellent les sorcières de Macbeth et l'amour confiant et innocent de Morounké pour Isola dans $D u$ Rouge de Cam sur les feuilles évoque les tendres héroïnes shakespeariennes. Dans la Danse de la Forêt, la forêt fréquentée par les vivants rappelle la forêt des Ardennes shakespearienne, tandis que la forêt habitée par les Esprits et les Dieux s'apparente à la forêt magique du Songe d'une nuit d'été. D'autre part, les revenants de cette pièce, les deux morts qui viennent demander des comptes aux vivants, sont la sinistre réplique du fantôme du père d'Hamlet criant vengeance. De plus, les rituels traditionnels 
autour desquels sont construites les pièces tragiques de l'auteur nigérian possèdent une étonnante parenté avec le théâtre shakespearien, qui a aussi ses boucs-émissaires, ses scènes d'exorcisme et ses rituels de purgation.

Les emprunts à la Bible, source inépuisable de méditation et de poésie, conditionnent de nombreuses séquences de ce théâtre aux dimensions multiples.

Dans la Récolte de Kongi, à la recherche de symboles s'appliquant à son règne, Kongi se voit dans le rôle du Christ, comme le Messie, le Jésus d'Isma. Néanmoins, dans le calendrier d'Isma, la fête de la Nativité du Christ sera remplacée par la Fête de la Récolte de l'Igname, l'an I de l'ère de la Récolte de Kongi. Dans la réalité, Kongi est un faux messie, un messie de mort; tandis que Daodu, le neveu de l'oba, incarne l'abondance de vie et la promesse $d$ 'une seconde venue:
À ma première venue
Une couronne d'épines
À ma première venue
Une couronne d'épines
Le hérisson aventureux
S'est empalé sur des clous.
Mais maintenant lors de cette seconde venue
C'est la saison de la Récolte
Lors de cette seconde venue
C'est l'igname qu'on va piler
Je suis né dans la joie
Je suis venu assoiffé de vin de palme
$C^{\prime}$ est le règne de la paix.

La Bible imprègne aussi Fous et Spécialistes, dont le leitmotif, constamment repris par le Vieillard a demi fou et par ses acolytes, est une parodie du texte sacré: «"Comme» était, est maintenant, sera à jamais...» «Bi o ti wa.»

Il existe donc de multiples sources européennes et américaines, anciennes et récentes, du théâtre de Wole Soyinka. D'ailleurs, la recherche d'un theâtre total reflète également une 
des tendances actuelles du théâtre contemporain. Cette parenté avec le théâtre d'Occident a quelque chose de rassurant pour le traducteur utilisant une langue européenne; encore faut-il qu'il sache évoquer les appartenances occidentales des pièces, sans en exagérer l'importance, ni faire disparaître les particularismes de ce théâtre. Les rituels de la Danse de la Forêt, par exemple, appartiennent tout $d$ 'abord aux pratiques religieuses yoruba, même s'ils évoquent aussi l'univers shakespearien.

\section{La «double appartenance»: la culture nigériane contemporaine}

Dans sa vie comme dans ses écrits, Wole Soyinka a la réputation d'illustrer la "double appartenance" - le double take - caractéristique, dit-on, de la littérature africaine contemporaine, en laquelle on croit voir constamment s'affronter tradition et modernisme, passé et présent, Afrique et Europe, animisme et christianisme.

Le dramaturge nigérian transcende, en réalité, le simple conflit des cultures. Dans la Mort et l' $́$ cuyer du Roi, le rôle néfaste dévolu au colonisateur est présenté comme un épiphénomène qui n'eut sur le vieil Elesin (ou Écuyer du Roi) qu'un effet catalyseur; si, emprisonné par l'administrateur européen, l'Écuyer du Roi ne peut rejoindre dans la mort son oba, comme le lui commande la coutume, c'est à lui, à son trop grand amour de la vie et à sa lâcheté devant la mort, que cette faute est imputable, et non à l'influence du District Officer (équivalent britannique du commandant de cercle). Plutôt que d'être replacé dans le contexte colonial, le comportement de l'Écuyer est évalué selon les critères de sa société; Elesin n'est pas présenté comme la victime du conflit des valeurs occidentales et africaines, mais comme un vieillard indigne qui a manqué à la coutume.

A de nombreux égards, néanmoins, la culture nigériane contemporaine se caractérise par l'amalgame en profondeur des cultures traditionnelles et des influences afro-européennes. Le théâtre de Wole Soyinka, qui fait une si large place tant à la culture-source yoruba qu'aux sources anglaises, intègre, dans le cadre précisément du double take, la composante anglo-nigériane, 
avec ses formes originales d'acculturation, ou de mélange des cultures.

\section{1) L'amalgame linguistique: l'anglais pidgin}

Il existe sur les côtes d'Afrique des langues véhiculaires permettant à des locuteurs dont les langues maternelles diffèrent de se comprendre. Au Nigéria, l'anglais pidgin est formé d'un mélange de vocables et de structures grammaticales anglaises et d'éléments empruntés aux langues locales. Les écrivains utilisent ce parler des villes en vue d'effets comiques ou par souci de réalisme. La traduction de cette langue en français pose des problèmes quasi insolubles; $l^{\prime}$ Afrique francophone ne dispose que de "petits nègres», langues bien pauvres par rapport au pidgin des ex-colonies anglaises; de plus, ce «dialecte» inspire le mépris dans les territoires francophones: une troupe martiniquaise qui représentait les Métamorphoses de Frère Jéro au Festival de la francophonie, à Limoges, refusa de remplacer les répliques en pidgin par leur traduction en créole, estimant que, par cette transposition, la langue des Antilles aurait été ravalée au niveau d'un charabia.

Optant pour une solution «africaine», les traducteurs de la Route ont choisi de rendre la langue populaire des villes nigérianes par le "petit français" d'Abidjan, qui est une langue moins riche mais de même nature; ce faisant, dans la Route, l'intelligibilité est parfois sacrifiée; mais les effets comiques et la présentation réaliste de la vie quotidienne des gens de la route compensent jusqu'à un certain point cette difficulté supplémentaire de la pièce. Incarnant un «millionnaire africain» dans un jeu de rôles, deux chauffeurs imaginent en ces termes le bonheur de cet "homme qu'on pelé-lui millionnaire»: «La verté est bon. L'homme qui a gagné beaucoup larzent i gagné la force. Zé va bouffé la vie zouqua on dit pas. Zé va bouffé la vie zou Ka lé Dié i vazalou» («La vérité est que celui qui a l'argent a le pouvoir. Je vais tellement profiter de la vie que Dieu en sera jaloux.» [1988, pp. 29-30]) Cette technique a son revers puisque les traducteurs ont dâ transposer dans une note le «petit français» de leurs personnages en français normal, procédé évidemment inutilisable 
sur une scène de théâtre. Néanmoins, en comparaison des ingénieuses trouvailles des traducteurs de la Route, la version française du Sergent Amusa fait bien piètre figure, lorsque, dans la Mort et l'Écuyer du Roi, au nom du gouvernement, Amusa enjoint les femmes du marché de livrer l'Écuyer pour empêcher son suicide: «Le gouvernement dit devoir ce genre de chose cesser» (1986, p. 57), ou lorsqu'il exprime son respect des egungun dans un curieux mélange de français recherché et de "petit nègre». "Madame, j'arrête les meneurs qui font du bruit et sèment le désordre mais moi je touche pas egungun. Egungun lui-même je touche pas» (1986, p. 39). Dans les Métamorphoses de Frère Jéro, le pidgin sommaire de Tchoumé (l'ancien souffredouleur de frère Jéro), le plus souvent pure invention de la traductrice - «Comment vous i va faire? Vous i sait pas jouer trompette» (1986, p. 31) - a néanmoins le mérite d'être intelligible et la comparaison établie par cet esprit simple entre un art musical agrémenté de fioritures et une bonne soupe pimentée, est d'un effet comique certain.

\section{2) L'anglais nigérianisé}

La culture anglo-nigériane se manifeste, en second lieu, par l'emploi d'un anglais nigérianisé dans la bouche des personnages ruraux et dans les séquences poétiques. Par convention littéraire, les paysans (rois et manants) qui, dans la vie normale, s'exprimeraient en yoruba, utilisent une forme d'anglais fortement nigérianisée, particulièrement difficile à traduire dans une autre langue, car elle est émaillée d'images, de proverbes, d'allusions aux croyances yoruba et de citations empruntées a l'orature (contes, chants, prieres, incantations divinatoires, proverbes, devinettes) et à l'histoire passée de la nation yoruba. Les métaphores et les proverbes, ces "chevaux ailés de la parole» (horses of speech), qui sont censés rendre la texture même de la langue et de la tradition yoruba, présentent une grande opacité pour le non-Yoruba. Avec un humour bon enfant, Wole Soyinka parodie cette forme de langage dont les vieux sages jadis si respectés des villages usent et abusent: avec son « $\mathrm{A}$ bon entendeur, silence» et un déluge de dictons, Agboréko, l'Ancien des Lèvres Closes de la Danse de la Forêt, fait figure de vieux 
radoteur, mais il illustre aussi, par son discours orné de formules sentencieuses, souvent ineptes, véritable gageure pour le traducteur, le rôle majeur du proverbe et du cliché dans le discours africain:

Le pied du serpent n'est pas double comme celui de l'homme, ni centuple comme celui du mille-pattes, mais si Agéré pouvait danser aussi patiemment que le serpent, il déroulerait les anneaux de la chaîne qui conduit chez les morts... (1971, p. 71)

Les exemples les plus frappants de cette langue territorialisée à l'extrême se rencontrent dans la Route et dans la Mort et l'Écuyer $d u$ Roi, ces deux drames «métaphysiques» enracinés dans les croyances et pratiques ancestrales des Yoruba. Le premier retrace la quête de l'ultime secret du Verbe par le Professeur, ce collectionneur de signes indéchiffrables et de formules magiques:

Je suis un glaneur, il est vrai [...] Je reste fidèle à l'air et à la terre ouverte, baigne mes pieds dans la rosée matinale, glanant sur la route mots et verbes épars. $(1988$, p. 143)

Dans le second, l'Écuyer, s'incarnant, au nom des êtres vivants, dans «'oiseau-qui-dit-pas-moi (the Not-I-Bird)» lance, dans un langage allusif, un refus angoissé à la mort: à son appel, le fermier «entame un bref dialogue avec ses jambes» (formule imagée, calquée sur le youba), le sculpteur qui vient de lancer son opélé sur les tablettes magiques (pour consulter Ifa, le dieu de la divination) est saisi d'un tremblement, et, à la vue d'Osanyin, "l'oiseau messager venu du cœur de la sagesse d'Ifa", le prêtre se calfeutre dans sa demeure. «'Pas moi', 'pas moi' devint le nom/ De l'oiseau tourmenté, cet oisillon/ Que la mort trouva niché parmi les feuilles» (1988, p. 19). La traduction de ces incursions dans la métaphysique des Yoruba requiert une culture étendue, une grande familiarité avec la pensée yoruba et une sensibilité poétique aiguë.

\section{3) Les limites extrêmes de l'acculturation: une langue éclatée}

Le théâtre de Soyinka doit son originalité, mais aussi, parfois, son obscurité aux rencontres, amalgames ou heurts, des multiples 
courants qui l'alimentent. Non seulement les protagonistes s'expriment dans diverses variétés d'anglais, mais ils utilisent des registres linguistiques divers, placés sous le signe du défi aux conventions, de l'innovation et de la jonglerie verbale. Ils adoptent tour à tour la langue pseudo-scientifique des pseudoélites intellectuelles, la rhétorique creuse des hommes au pouvoir et le langage torturé des élites sous le joug.

\section{a) La langue du positivisme scientifique}

Les conseillers de Kongi, qui ont pour mission de trouver un symbole descriptif du règne «éclairé» de leur maître, imaginent un «symbole scientifique» qui, au lieu des proverbes et poèmes cultivés par les hommes de la tradition, contiendrait «des idéogrammes sous forme de formules algébriques» (1988, p. 13). Le président Kwamé Nkrumah aurait le premier tenté de définir progrès et forces de réaction au moyen d'équations algébriques et de symboles positifs dans l'un de ses essais politiques, le Consciencisme. Simultanément, les radios nationales d'Isma diffusent les slogans inventés par les inconditionnels du Kongisme pour endoctriner les Ismites, ou habitants d'Isma, État où règnent en maîtres les «ismes» ou futiles abstractions dont Kongi nourrit son discours politique: « $D$ 'isme à isme, car isme est isme $d$ 'ismes et d'ismes sur un fond d'absolutisme». Les haut-parleurs rappellent à la population que «Les Ismites sont des hommes qui [...] Militent» et que «Les Ismites sont forts [...] comme la Dynamite» (1988, pp. 22-23). Ces tentatives d'endoctrinement par les médias expriment, par l'emploi d'un langage brutal et parfois incohérent, les prétentions et la volonté destructrice du tyran.

\section{b) Le cri de révolte}

C'est précisément le «charabia» du dramaturge nigérian que dénonce sans aménité le critique américain Bernth Lindfors. Pourtant, la langue désarticulée du Vieillard et des Mendiants dans Fous et Spécialistes, incriminée par le critique texan, se

3. Bernth Lindfors, «Wole Soyinka, When are you coming home?» Yale French Studies, $n^{\circ} 53$ (1976). 
justifie pleinement par les origines hybrides de l'écriture de l'auteur et par la révolte qui l'inspire contre tous les impérialismes culturels, sociaux et politiques. Pour exprimer son refus des conventions, il fait violence à la langue anglaise, recherche le terme rare, l'expression tarabiscotée, les courtes racines anglosaxonnes, les longs termes pédants latins et grecs, les assonances, les allitérations, les effets burlesques, les formules explosives qui bousculent la pensée en même temps que la langue. Le cri de révolte est incontestable et la formulation en est sans appel:

O kyste, ô toi kyste, ô écharde logée dans la flèche de l'arrogance, dans le dogue de dogme, le tic-tac de hérétique, le tique de politique, la moquerie de démocratie, la marcescence de marxisme, le tic de fanatique, le hou! de bouddhisme, le mets de Mahomet, le trait d'union dans Jésus-Christ, le point sur l'i de moi, le cul de culte, la vache de l'ashram, la botte de Kiboutz, le pet de prêtre, le double pet d'un prêtre parfait, oh! comment oses-tu lever la patte, ô dogue de dogme, et marquer de l'odeur de ta vie de chien le Réverbère de la destinée, ô toi CAVITÉ DANS LE VIDE DU NÉANT!

La philosophie nihiliste qui se dégage de cette tirade met à nu, dans un monologue qui confine a l'hystérie, les scandales de la civilisation contemporaine; au cannibalisme que d'aucuns prêtent aux Africains des tribus est opposée, ici et dans d'autres pièces, la barbarie brutale des pseudo-élites qui dissimulent leurs vices sous de savantes constructions philosophiques, derrière les mensonges de la religion de "Comme" et dans les orgies de chair humaine auxquelles s'adonnent les puissants au cours de guerres fratricides. La hardiesse des critiques proférées par Wole Soyinka à l'encontre des grands de ce monde, le non-conformisme qui parcourt son théâtre, la véhémence du ton sonnent comme autant de mises en garde contre l'effondrement universel des valeurs et, plus particulièrement, contre les Africains oublieux des valeurs traditionnelles. La langue heurtée jusqu'à l'incohérence exprime l'indignation sans borne du dramaturge. Peut-être exprime-t-elle aussi le sentiment d'une intégration inachevée. Aussi profondément implantée soit-elle dans la société nigériane d'aujourd'hui, la culture anglo-nigériane a besoin, pour assurer sa survie, de la voix stridente de «rebelles» de la trempe d'un Wole Soyinka. Pas 
plus toutefois que le Père de la forêt, le dramaturge ne doute des humains, ni ne perd

l'espoir pourtant, l'espoir que si je parvenais à faire jaillir de leur esprit torturé une étincelle de conscience, peut-être alors, peut-être qu'un nouveau départ... (1971, p. 122)

Plutôt que de se laisser rebuter par l'obscurité et la confusion de certaines scènes de ce théâtre, le lecteur/traducteur doit les interpréter comme les signes d'une saine révolte contre les iniquités de la société nigériane et de tentatives courageuses pour contribuer à l'essor d'une culture riche en promesses.

\section{Conclusion}

Il faut avoir à l'esprit toutes ces composantes pour traduire Wole Soyinka en français, en étant de cette façon prévenu aussi bien contre une vision passéiste de l'Afrique que contre l'eurocentrisme, et en ayant conscience, avec Wole Soyinka, de l'existence au Nigéria d'une culture moderne très particulière, encore mal assise et menacée par toutes sortes de forces rétrogrades. Les pièces du dramaturge nigérian doivent précisément leur difficulté, leur hermétisme, mais aussi leur beauté et leur richesse, à l'impact de cette culture-source anglo-nigériane où se côtoient, s'opposent et se fondent, inextricablement, des données linguistiques, sociologiques, ethniques, religieuses et humaines d'origines diverses. Tel est le défi auquel sont confrontés aussi bien l'écrivain Wole Soyinka dans son théâtre que le traducteur de ses ceuvres.

Université de Paris XII/Val-de-Marne 


\section{Références}

\section{Traductions, 1968-1971:}

Le Lion et la Perle (1968). Trad. Chuto et Laburthe-Tolra, Paris, éd. Clé.

La Danse de la Forêt (1971). Trad. Élisabeth Janvier, Honfleur, éd. P. J. Oswald.

Les Gens des Marais, Un Sang Fort et les Tribulations de Frère Jéro (1971). Trad. Élisabeth Janvier, Honfleur, éd. P. J. Oswald.

\section{Traductions, 1986-}

Les Métamorphoses de Frère Jéro (1986). Trad. Élisabeth Janvier, Paris, éd. Présence Africaine.

La Mort et l'Écuyer du Roi (1986). Trad. Thierry Dubost, Paris, éd. Hatier-CEDA.

La Route (1988). Trad. Christiane Fioupou et Samuel Millogo, Paris, éd. Hatier-CEDA.

La Récolte de Kongi (1988). Trad. Éliane Utudjian Saint-André et Claire Pergnier, Paris, éd. Silex.

Les Bacchantes d'Euripide - Rite de Communion (1989). Trad. Étienne Galle, Paris, éd. Silex.

Du Rouge de Cam sur les Feuilles (1990). Trad. Éliane Utudjian Saint-André et Claire Pergnier, Paris, éd. Nouvelles du Sud.

Fous et Spécialistes (1990). Trad. Éliane Utudjian Saint-André et Claire Pergnier, Paris, éd. Nouvelles du Sud.

Requiem pour un futurologue (1990). Trad. Étienne Galle, Paris, éd. Nouvelles du Sud. 
RÉSUMÉ: Processus d'acculturation et problèmes de traduction: le théâtre de Wole Soyinka - Cette étude traite des déterminations linguistiques et culturelles que fait peser une culture-source peu familière sur la traduction en français du théâtre de langue anglaise de l'auteur nigérian Wole Soyinka, prix Nobel de littérature (1986). L'ethnie yoruba fournit à ces pièces une langue polytonale, une civilisation enracinée dans le sacré et un théâtre ambulant opératique. Les influences occidentales se reconnaissent à l'utilisation de l'anglais standard par les personnages membres de l'élite cultivée, de mots-clés révélateurs d'idéologies par les personnages représentatifs et de modèles littéraires occidentaux. La composante anglo-nigériane, synthèse plus ou moins cohérente, mais toujours très riche, de toutes les influences, se distingue par l'emploi de l'anglais pidgin, $d^{\prime} u n$ anglais nigérianisé et d'un style heurté, parfois hermétique, exprimant la souffrance et la rébellion. Les trois composantes de ce théâtre (indissociables dans la réalité) exigent du traducteur des techniques variées, une culture étendue et une grande sensibilité poétique. Il revient au traducteur francophone de trouver des équivalents français susceptibles de rendre des faits de civilisation africains, issus de processus d'acculturation complexes.

ABSTRACT: Acculturation process and translation problems: the theatre of Wole Soyinka - This paper deals with the linguistic and cultural determinations imposed by a little-known (Anglo-African) source-culture on translations into French of plays by the Anglophone Nigerian writer, 1986 Nobel-prize winner, Wole Soyinka. The Yoruba background provides these plays with a tone-language, a culture rooted in animism and techniques borrowed from a partly traditional, partly modern itinerant operatic theatre. Western influences show through in the use of standard English by the plays' Western-educated protagonists, of key-words and phrases pointing to the plays' ideologies and of Western literary models. The Anglo-Nigerian elements, forming a rich though at times hardly coherent synthesis of every source and influence, stand forth in the prevalence of Nigerian pidgin, image-laden Nigerianized English and a tense, jerky and even abstruse style expressing both suffering, rebellion and a search for ultimate truths. 